OPEN ACCESS

Edited by:

Ina M. Tarkka,

University of Jyväskylä, Finland

Reviewed by:

Charalambos Costas Charalambous, University of Nicosia, Cyprus

Cristiano De Marchis,

Roma Tre University, Italy

*Correspondence:

Trisha M. Kesar

tkesar@emory.edu

Specialty section:

This article was submitted to

Neurorehabilitation,

a section of the journal

Frontiers in Neurology

Received: 02 December 2020

Accepted: 05 March 2021

Published: 30 March 2021

Citation:

Spencer J, Wolf SL and Kesar TM (2021) Biofeedback for Post-stroke Gait Retraining: A Review of Current

Evidence and Future Research

Directions in the Context of Emerging Technologies.

Front. Neurol. 12:637199. doi: 10.3389/fneur.2021.637199

\section{Biofeedback for Post-stroke Gait Retraining: A Review of Current Evidence and Future Research Directions in the Context of Emerging Technologies}

\author{
Jacob Spencer ${ }^{1}$, Steven L. Wolf ${ }^{1,2,3,4}$ and Trisha M. Kesar ${ }^{1 *}$ \\ ${ }^{1}$ Division of Physical Therapy, Department of Rehabilitation Medicine, Emory University School of Medicine, Atlanta, GA, \\ United States, ${ }^{2}$ Department of Medicine, Emory University School of Medicine, Atlanta, GA, United States, ${ }^{3}$ Department of \\ Cell Biology, Emory University School of Medicine, Atlanta, GA, United States, ${ }^{4}$ Center for Visual and Neurocognitive \\ Rehabilitation, Atlanta VA Health Care System, Decatur, GA, United States
}

Real-time gait biofeedback is a promising rehabilitation strategy for improving biomechanical deficits in walking patterns of post-stroke individuals. Because wearable sensor technologies are creating avenues for novel applications of gait biofeedback, including use in tele-health, there is a need to evaluate the state of the current evidence regarding the effectiveness of biofeedback for post-stroke gait training. The objectives of this review are to: (1) evaluate the current state of biofeedback literature pertaining to post-stroke gait training; and (2) determine future research directions related to gait biofeedback in context of evolving technologies. Our overall goal was to determine whether gait biofeedback is effective at improving stroke gait deficits while also probing why and for whom gait biofeedback may be an efficacious treatment modality. Our literature review showed that the effects of gait biofeedback on post-stroke walking dysfunction are promising but are inconsistent in methodology and therefore results. We summarize sources of methodological heterogeneity in previous literature, such as inconsistencies in feedback target, feedback mode, dosage, practice structure, feedback structure, and patient characteristics. There is a need for larger-sample studies that directly compare different feedback parameters, employ more uniform experimental designs, and evaluate characteristics of potential responders. However, as these uncertainties in existing literature are resolved, the application of gait biofeedback has potential to extend neurorehabilitation clinicians' cues to individuals with post-stroke gait deficits during ambulation in clinical, home, and community settings, thereby increasing the quantity and quality of skilled repetitions during task-oriented stepping training. In addition to identifying gaps in previous research, we posit that future research directions should comprise an amalgam of mechanism-focused and clinical research studies, to develop evidence-informed decision-making guidelines for gait biofeedback strategies that are tailored to individual-specific gait and sensorimotor impairments. Wearable sensor technologies have the potential to transform gait biofeedback and provide greater access and wider array of options for clinicians while lowering rehabilitation costs. 
Novel sensing technologies will be particularly valuable for telehealth and home-based stepping exercise programs. In summary, gait biofeedback is a promising intervention strategy that can enhance efficacy of post-stroke gait rehabilitation in both clinical and tele-rehabilitation settings and warrants more in-depth research.

Keywords: gait rehabilitation, real-time biofeedback, locomotion, hemiparesis, cerebrovascular accident

\section{INTRODUCTION}

Biofeedback is a process by which an external stimulus derived from previously covert physiological or motor performance data is provided to an individual in real time to induce selfmodification of a behavior (1-6). Applications of biofeedback can be as disparate as cuing an individual with a tension headache to relax offending muscles through electromyographic (EMG) feedback and retraining standing balance through visual feedback regarding ongoing foot center of pressure data $(3,7)$. Biofeedback can also be used in locomotor rehabilitation to promote restitution of appropriate gait patterns (1). During gait biofeedback training, a target variable such as push off force or knee angle at mid-stance, is conveyed as a comprehensible visual, auditory, or tactile signal alerting the user of their relative success in reaching the targeted gait parameter $(4,8)$ (Figure 1A). Accurate and instantaneous biofeedback can be provided for every step with the goal of addressing deleterious gait abnormalities, which often require frequent and specific cuing to correct $(1,9-11)$.

Stroke is a leading cause of adult disability and a majority of stroke survivors present with post-stroke gait dysfunction resulting in compromised community participation and quality of life $(2,12-14)$. The prevalence and impact of residual gait deficits after stroke positions post-stroke individuals as ideal candidates for gait biofeedback as a treatment modality, especially as an adjunct to other clinically-relevant and evidencesupported gait rehabilitation treatments such as high intensity locomotor training $(15,16)$. Despite the compelling rationale for biofeedback as a gait training tool, its use is relatively uncommon in clinical practice.

While there is little research on barriers limiting clinical use of biofeedback, costly and cumbersome equipment combined with a lack of research consensus may be contributing factors. However, technological advances, including the evolution of wearable sensors, may resolve the former problem and serve to make biofeedback gait training a more realistic intervention choice for clinicians (17). An additional benefit of wearable sensorbased biofeedback may include the ability to convey clinicianselected cues during a home exercise or telehealth program, enhancing the efficacy of clinical rehabilitation and carryover of therapeutic gains to community ambulation (17). Of course, the newfound accessibility granted by wearable sensor technology and telehealth applications will be of little value if biofeedback itself is an ineffective post-stroke gait training intervention.

Therefore, the objectives of this review are 2-fold: (1) to evaluate the current state of biofeedback literature that pertains to post-stroke gait training; and (2) to determine future research directions related to gait biofeedback with a special focus on application of new technologies. To achieve these objectives, the literature search was designed to include multiple feedback modes, target parameters for gait retraining, and methods of post-stroke gait biofeedback as possible, with the intent to synthesize our current knowledge regarding the methodological parameters and effects of post-stroke gait biofeedback, while also outlining areas for future research.

\section{LITERATURE SEARCH METHODS}

This literature review categorizes the factors that influence the efficacy of biofeedback as a gait training intervention for post-stroke individuals and identifies knowledge gaps in the evidence landscape. The literature review included searches of databases, including PubMed and PEDro. All articles available on PEDro were categorized based on their PEDro score. The following search terms were used in PubMed: (biofeedback[tw] OR "Biofeedback, Psychology"[Mesh] OR "electromyographic biofeedback"[tw] OR "EMG BFB"[tw] OR EMGBFB[tw] OR EMG-BFB[tw]) AND ("stroke rehabilitation" $[\mathrm{tw}] \mathrm{OR}$ "Stroke Rehabilitation" [Mesh] OR "Stroke/rehabilitation" [Mesh]) AND (gait[tw] OR "Gait"[Mesh] OR walking[tw] OR "Walking”[Mesh] OR "mobility limitation"[tw] OR "Mobility Limitation"[Mesh]) AND English[lang] AND (“1970/1/1”[Date - Publication]: “2020/4/1”[Date - Publication]) NOT ("animals"[MeSH Terms] NOT "humans"[MeSH Terms]).

\section{Eligible Studies}

All articles that appeared in the initial database search were evaluated for relevance by author JS. Randomized Control Trials (RCTs) scoring $>6 / 10$ on the PEDro scale were given preference. Because our goal was to capture a wide variety of experiment designs lower scoring RCTs and non-RCTs were also included if they used unique or rigorous methodology. Articles exclusively involving biofeedback provided during static standing or marching in place as well as provided in conjunction with robotic gait training were excluded.

We were unable to find systematic reviews specifically addressing biofeedback for post-stroke gait rehabilitation, although two reviews covered somewhat related topics and merit mention. Woodford and Price (14) performed a review evaluating the efficacy of EMG biofeedback training following stroke, and found that overall, biofeedback did not demonstrate treatment benefits relative to standard physical therapy. However, the Woodford and Price review was not specific to gait and included studies assessing the efficacy of EMG biofeedback in improving upper limb activity (14). Woodford and Price also focused exclusively on EMG biofeedback (14). Another systematic review by Stanton et al. (2) found that 
A

Gait Biofeedback

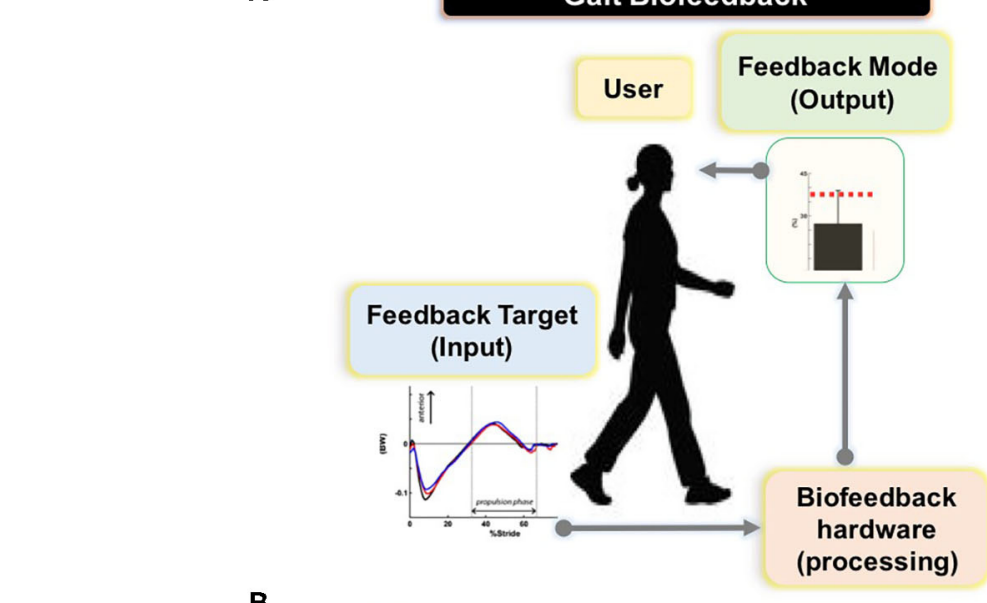

B

\section{Types of Gait Biofeedback}

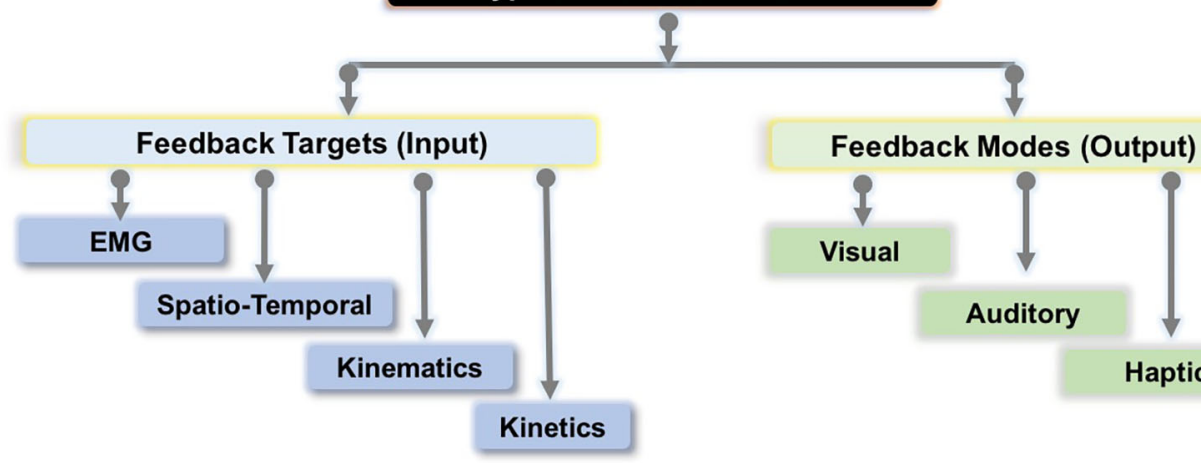

C

Methodological factors that influence the response to biofeedback

Practice Structure and Feedback Schedule

- Limited research shows effectiveness of faded feedback schedule with variable practice structure

Dosing

- Session duration and number of treatments

vary greatly across studies
Patient Selection Criteria

- Common exclusion criteria: mini-mental score<24 and visual deficits

- Inclusion criteria and measurement tests for motor deficits vary across studies

- Time post-stroke: more research in chronic and late subacute

than acute and early subacute stages

FIGURE 1 | (A) Schematic showing the setup for gait biofeedback, where a targeted gait parameter (e.g., anterior-posterior ground reaction force or electromyographic (EMG) activation) is measured, processed, and real-time, accurate information about the ongoing gait parameter is provided to the user via a feedback mode (e.g., audio-visual interface). (B) The flowchart shows types of feedback targets-EMG, spatio-temporal (e.g., step length, cadence), kinematic (e.g., joint angles), kinetic (e.g., ankle moment) as well as different feedback modes (e.g., visual, audio, haptic) that we summarize in our review, and provided by Stanton et al. (C) Summary of methodological parameters that we identified as factors influencing previous research results on biofeedback targeting stroke gait deficits.

lower extremity biofeedback delivered during movement from sitting to standing, standing, or ambulation improved lower limb activity in individuals post-stroke compared to traditional therapy, but in that review, nine of the 18 trials cited were unrelated to ambulation (2) and only four studies assessed progress at any time point other than immediately following the intervention (2). As a result, Stanton et al. failed to find support for the long-term efficacy of lower limb biofeedback (2). Finally, a mapping review by van Gelder et al. (18), sought to categorize existing gait biofeedback literature by both quality and content, but was not exclusive to individuals post-stroke (18). While this review is valuable, post-stroke individuals present unique sensorimotor and gait deficits (19), which merit separate analysis and synthesis, and was the specific focus of the current manuscript.

While there have been a few literature reviews on biofeedback as a rehabilitation modality, previous work has not focused exclusively on stroke as a neuropathology and biofeedback as a basis for specifically targeting gait deficits. Because a goal of the current review was to capture a wide variety of potential methods 
TABLE 1 | Summary of relevant characteristics of selected randomized control trials included in the review.

\begin{tabular}{|c|c|c|c|c|c|c|c|c|c|c|c|c|}
\hline \multirow[t]{2}{*}{ Study } & \multirow[t]{2}{*}{ Feedback target } & \multirow[t]{2}{*}{$\begin{array}{l}\text { Feedback } \\
\text { mode }\end{array}$} & \multirow[t]{2}{*}{$\begin{array}{l}\text { Motor learning } \\
\text { strategies }\end{array}$} & \multirow[t]{2}{*}{ Dosing } & \multirow[t]{2}{*}{$\begin{array}{l}\text { Time } \\
\text { post-stroke }\end{array}$} & \multirow[t]{2}{*}{$\begin{array}{l}\text { Key participant inclusion and } \\
\text { exclusion criteria }\end{array}$} & \multirow[t]{2}{*}{ Control group } & \multicolumn{2}{|c|}{ Sample size } & \multicolumn{2}{|c|}{$\begin{array}{l}\text { Key outcomes and } \\
\text { descriptive statistics }\end{array}$} & \multirow[t]{2}{*}{ Statistical results } \\
\hline & & & & & & & & $\begin{array}{l}\text { Feedback } \\
\text { Group }\end{array}$ & $\begin{array}{l}\text { Control } \\
\text { Group }\end{array}$ & $\begin{array}{l}\text { Experimental } \\
\text { Group }\end{array}$ & Control Group & \\
\hline & & & & & & & & & & $\begin{array}{l}10 \text { meter walk tes } \\
\text { (Pre to Post) }\end{array}$ & st (seconds) & \\
\hline \multirow[t]{2}{*}{ Choi et al. (20) } & $\begin{array}{l}\text { Kinetic (weight-bearing } \\
\text { during stance) }\end{array}$ & Auditory & $\begin{array}{l}\text { Walking only allowed to } \\
\text { continue when } 50 \% \text { of } \\
\text { total body weight was } \\
\text { placed through stance } \\
\text { phase leg }\end{array}$ & $\begin{array}{l}18 \text { sessions, } 20 \\
\text { min/session for } 3 \\
\text { weeks }\end{array}$ & $\begin{array}{l}\text { Not specified, } \\
\text { patients recrited } \\
\text { from rehabilitation } \\
\text { center }\end{array}$ & $\begin{array}{l}\text { Inclusion: Brunnstrom score } \\
\text { between } 3 \text { and } 5 \text {, able to walk } \\
\text { independently Exclusion: Modified } \\
\text { ashworth > } 1 \text { in dorsillexor, } \\
\text { Mini-Mental score }<24\end{array}$ & $\begin{array}{l}\text { General } \\
\text { overground gait } \\
\text { training }\end{array}$ & $n=12$ & $n=12$ & $\begin{array}{l}23(14.6) \text { to } \\
17.2(10.1)\end{array}$ & $\begin{array}{l}18.1(16.4) \text { to } \\
16.9(15.6)\end{array}$ & $\begin{array}{l}\text { Significant improvement in } 10 \text { min walk } \\
\text { test }(p=0.02) \text {, functional gait } \\
\text { assessment, COP path length with } \\
\text { eyes open and eyes closed in } \\
\text { experimental group relative to control }\end{array}$ \\
\hline & & & & & & & & & & $\begin{array}{l}\text { Change in step sy } \\
\text { (Pre-post) }\end{array}$ & ymmetry index & \\
\hline \multirow[t]{2}{*}{$\begin{array}{l}\text { Druzbicki et al. } \\
\text { (21) }\end{array}$} & $\begin{array}{l}\text { Spatio-temporal (Step } \\
\text { length) }\end{array}$ & Visual & $\begin{array}{l}\text { Step-length and gait } \\
\text { speed increased, } \\
\text { bodyweight support } \\
\text { decreased progressively } \\
\text { based on performance. } \\
\text { Feedback present } \\
\text { throughout training. }\end{array}$ & $\begin{array}{l}15 \text { sessions, } 30 \\
\text { min/session, for } 3 \\
\text { weeks }\end{array}$ & Subacute & $\begin{array}{l}\text { Inclusion: Brunnstrom 2-3, able to } \\
\text { walk unassisted Excllusion: Visual } \\
\text { deficits, Mini-Mental score } 24\end{array}$ & $\begin{array}{l}\text { Body-weight } \\
\text { supported } \\
\text { treadmill training } \\
\text { without } \\
\text { biofeedback }\end{array}$ & $n=15$ & $n=15$ & $0.03(0.02)$ & $0.02(0.02)$ & $\begin{array}{l}\text { No significant difference }(p=0.902) \text { in } \\
\text { step-symmetry index between groups }\end{array}$ \\
\hline & & & & & & & & & & $\begin{array}{l}\text { Step-symmetry in } \\
\text { and 6-month follo }\end{array}$ & $\begin{array}{l}\text { iddex (at Pre } \\
\text { w up) }\end{array}$ & \\
\hline \multirow[t]{2}{*}{$\begin{array}{l}\text { Druzbicki et al. } \\
\text { (22) }\end{array}$} & $\begin{array}{l}\text { Spatio Temporal } \\
\text { (Step-length) }\end{array}$ & Visual & $\begin{array}{l}\text { Constant feedback, speed } \\
\text { and step length adjusted } \\
\text { according to task } \\
\text { performance }\end{array}$ & $\begin{array}{l}10 \text { sessions, } 20 \\
\text { min/session, for } 2 \\
\text { weeks }\end{array}$ & Chronic & $\begin{array}{l}\text { Inclusion: Independent gait, } \\
\text { Brunnstrom 3-4 Exclusion: Visual } \\
\text { disturbances, Mini-Mental score } \\
<24\end{array}$ & Treadmill training & $n=15$ & $n=15$ & $\begin{array}{l}1.5(0.36) \text { to } \\
1.26(0.12)\end{array}$ & $\begin{array}{l}1.36(0.2) \text { to } \\
1.35(0.28)\end{array}$ & $\begin{array}{l}\text { No significant changes in step-symetry } \\
\text { index between experimental and } \\
\text { control group }\end{array}$ \\
\hline & & & & & & & & & & $\begin{array}{l}\text { Gait velocity }(\% \text { h/ } \\
\text { 6-month follow up }\end{array}$ & (s): Pre to & \\
\hline \multirow[t]{2}{*}{$\begin{array}{l}\text { Jonsdottir et al. } \\
\text { (23) }\end{array}$} & EMG (Plantar Flexors) & Auditory & $\begin{array}{l}\text { Variable practice and } \\
\text { faded feedback }\end{array}$ & $\begin{array}{l}20 \text { sessions, } \\
\text { including } \geq 15 \min \\
\text { of gait training }\end{array}$ & Chronic & $\begin{array}{l}\text { Inclusion: Able to walk } 10 \mathrm{~m} \\
\text { without assistance, volitional } \\
\text { triceps surae contraction } \\
\text { Exclusion: Visual or auditory } \\
\text { deficits, Mini-mental score }<24\end{array}$ & Standard care & $\begin{array}{l}n=10 \text { (at } \\
\text { Post) } n=9 \\
\text { (at 6-month } \\
\text { follow-up) }\end{array}$ & $\begin{array}{l}n=10 \text { (at } \\
\text { Post) } n=9 \\
\text { (at 6-month } \\
\text { follow-up) }\end{array}$ & $\begin{array}{l}28.7(10.8) \text { to } \\
38.8(8.9)\end{array}$ & $\begin{array}{l}26.3(11.9) \text { to } \\
28.4(14.3)\end{array}$ & $\begin{array}{l}\text { Significant }(p<0.05) \text { increase in gait } \\
\text { velocity, step length, and peak ankle } \\
\text { power in treatment group. No such } \\
\text { changes in control group }\end{array}$ \\
\hline & & & & & & & & & & $\begin{array}{l}\text { Reduction in hype } \\
\text { (degrees) }\end{array}$ & erextension & \\
\hline \multirow[t]{2}{*}{ Morris et al. (24) } & Kinematic (Knee angle) & Auditory & $\begin{array}{l}\text { Therapy and control group } \\
\text { treatments based on } \\
\text { principles of Motor } \\
\text { Relearning programme } \\
\text { (MRP) }\end{array}$ & $\begin{array}{l}45 \text { min of therapy, } \\
5 \text { days per week, } \\
\text { for } 4 \text { weeks, with } \\
330 \text { min spent on } \\
\text { knee control }\end{array}$ & Subacute & $\begin{array}{l}\text { Inclusion: Able to ambulate } 10 \mathrm{~m} \\
\text { without assistance, knee } \\
\text { hyperextension warranting } \\
\text { treatment Exclusion: Auditory } \\
\text { deficits }\end{array}$ & $\begin{array}{l}\text { Physical therapy } \\
\text { based on MRP } \\
\text { principles }\end{array}$ & $n=13$ & $n=13$ & $1.7(+/-1.8)$ & $0.4(+/-3.1)$ & $\begin{array}{l}\text { Treatment group showed signicicant }(0 \\
=0.011) \text { reduction in knee } \\
\text { hyperextension relative to the control } \\
\text { group after phase } 2\end{array}$ \\
\hline & & & & & & & & & & $\begin{array}{l}\text { Step symmetry ra } \\
\text { intervention }\end{array}$ & atio pre to post & \\
\hline \multirow[t]{2}{*}{$\begin{array}{l}\text { Brasileiro et al. } \\
\text { (25) }\end{array}$} & $\begin{array}{l}\text { Spatiotemporal (foot } \\
\text { placement, metronome) }\end{array}$ & $\begin{array}{l}\text { Auditory, } \\
\text { Visual, } \\
\text { Control } \\
\text { (three } \\
\text { groups) }\end{array}$ & & $20 \mathrm{~min}$ & Chronic & $\begin{array}{l}\text { Inclusion: Gait levels } 4-5 \text { on } \\
\text { Functional Ambulatory Category, } \\
\text { slow to moderate gait speed } \\
(<0.8 \mathrm{~m} / \mathrm{s}) \text {, Mini-Mental } \\
\text { score } 23-24 / 30 \text { (dependent on } \\
\text { social history) Exclusion: } \\
\text { Visual/auditory deficits }\end{array}$ & $\begin{array}{l}\text { Partial bodyweight } \\
\text { supported } \\
\text { treadmill training }\end{array}$ & $\begin{array}{l}n=10 \\
\text { (Group 1) } \\
n=20 \\
\text { (Group 2) }\end{array}$ & $n=10$ & $\begin{array}{l}\text { Group } 1: 1.43 \\
\text { (0.25) to } 1.34 \\
(0.23) \text { Group } 2: \\
1.49(0.34) \text { to } \\
1.58(0.47)\end{array}$ & $\begin{array}{l}1.61(0.43) \text { to } \\
1.53(0.41)\end{array}$ & $\begin{array}{l}\text { Treatment group displayed no } \\
\text { significant change in stride length } \\
\text { relative to the control group }\end{array}$ \\
\hline & & & & & & & & & & Change in gait sp & beed $(\mathrm{cm} / \mathrm{s})$ & \\
\hline \multirow[t]{2}{*}{$\begin{array}{l}\text { Sungkarat et al. } \\
\text { (26) }\end{array}$} & $\begin{array}{l}\text { Ambulation (Non-paretic } \\
\text { leg swing phase duration } \\
\text { in gait, paretic leg weight } \\
\text { bearing in standing) }\end{array}$ & Auditory & $\begin{array}{l}\text { Sensors adjusted to } \\
\text { progressively challenge } \\
\text { participant }\end{array}$ & $\begin{array}{l}15 \text { sessions, } \\
30 \text { min of gait } \\
\text { training in each }\end{array}$ & $\begin{array}{l}\text { equalized }<6 \\
\text { months and }>6 \\
\text { months } \\
\text { post-stroke }\end{array}$ & $\begin{array}{l}\text { Inclusion: Orpington prognostic } \\
\text { score 3.2-5.2 Exclusion: Impaired } \\
\text { cognition/communication }\end{array}$ & $\begin{array}{l}\text { Conventional gait } \\
\text { training }\end{array}$ & $n=17$ & $n=18$ & $12.24(11.7)$ & $4.06(6.0)$ & $\begin{array}{l}\text { Treatment group displayed significant ( } 10 \\
<0.05 \text { ) improvements in standing } \\
\text { symetry, gait symmetry, and gait speeed } \\
\text { compared to the control group }\end{array}$ \\
\hline & & & & & & & & & & \multicolumn{2}{|c|}{$\begin{array}{l}\text { Change in gait speed pre to } \\
\text { post intervention }(\mathrm{cm} / \mathrm{s})\end{array}$} & \\
\hline Jung et al. (27) & $\begin{array}{l}\text { Kinetic (force on pressure } \\
\text { sensing cane) }\end{array}$ & Auditory & $\begin{array}{l}\text { Feedback threshold } \\
\text { derived from objective } \\
\text { data, and modified weekly } \\
\text { if patient exhibited < } 20 \% \\
\text { error rate }\end{array}$ & $\begin{array}{l}30 \text { min/session, } 5 \\
\text { days per week, for } \\
4 \text { weeks }\end{array}$ & $\begin{array}{l}\text { Not explicitly } \\
\text { specified, but } \\
\text { patients recruited } \\
\text { from rehabilitation } \\
\text { center }\end{array}$ & $\begin{array}{l}\text { Inclusion: Functional classification } \\
\text { 2-3 Exclusion: Vestibular } \\
\text { symptoms, Mini-Mental score > }>24\end{array}$ & Gait training & $n=11$ & $n=10$ & $13.5(7.1-19.9)$ & $3.7(2.3-9.7)$ & $\begin{array}{l}\text { Treatment group displayed significant } \\
\text { improvements }(p<0.05) \text { in peak force } \\
\text { of cane, EMG activity in stance leg, } \\
\text { single limb support phase and gait } \\
\text { speed }\end{array}$ \\
\hline
\end{tabular}

The table lists that received scores of $\geq 6 / 10$ (moderate to high quality) on the Physical Therapy Evidence Database (PEDro) scale. All studies included in this table evaluated the relative efficacy of a biofeedback intervention provided during non-robotic gait training and compared to a non-biofeedback control group. The descriptive statistics are listed as average (standard deviation). 
TABLE 2 | Summary of relevant characteristics of other selected studies.

\begin{tabular}{|c|c|c|c|c|c|c|}
\hline Study & $\begin{array}{l}\text { Feedback } \\
\text { target }\end{array}$ & $\begin{array}{l}\text { Feedback } \\
\text { mode }\end{array}$ & $\begin{array}{l}\text { Time } \\
\text { post-stroke }\end{array}$ & Control group & $\begin{array}{l}\text { Key inclusion and } \\
\text { exclusion criteria }\end{array}$ & Results \\
\hline Afzal et al. (28) & Kinetic & $\begin{array}{l}\text { Combined } \\
\text { Haptic }\end{array}$ & Subacute & $\begin{array}{l}\text { Ambulation without } \\
\text { biofeedback, Repeated } \\
\text { measures design }\end{array}$ & $\begin{array}{l}\text { Able to ambulate } 10 \mathrm{ft} \\
\text { without assistance, } \\
\text { Brunnstrom stage }>3\end{array}$ & $\begin{array}{l}\text { Kinesthetic cues induced } \\
\text { significant improvements in } \\
\text { paretic muscle activity and } \\
\text { mediolateral trunk control } \\
\text { during walking. }\end{array}$ \\
\hline Aruin et al. (29) & Spatiotemporal & Auditory & Subacute & $\begin{array}{l}\text { Ambulation training without } \\
\text { biofeedback }\end{array}$ & $\begin{array}{l}\text { Able to ambulate } 4.5-6 \mathrm{~m} \\
\text { without assistance and } \\
\text { follow verbal instructions }\end{array}$ & $\begin{array}{l}\text { Biofeedback group had } \\
\text { significantly greater } \\
\text { step-width following } \\
\text { treatment. }\end{array}$ \\
\hline Bradley et al. (30) & EMG & $\begin{array}{l}\text { Visual or } \\
\text { Auditory }\end{array}$ & Subacute & $\begin{array}{l}\text { Same treatment techniques } \\
\text { without biofeedback }\end{array}$ & $\begin{array}{l}\text { No global amnesia or } \\
\text { dementia }\end{array}$ & $\begin{array}{l}\text { No significant difference } \\
\text { between groups in mobility } \\
\text { or activities of daily living. }\end{array}$ \\
\hline Genthe et al. (1) & Kinetic & $\begin{array}{l}\text { Visual and } \\
\text { Auditory }\end{array}$ & Chronic & $\begin{array}{l}\text { Ambulation without } \\
\text { biofeedback. Repeated } \\
\text { measures design }\end{array}$ & $\begin{array}{l}\text { Able to ambulate } \\
\text { continuously on treadmill for } \\
6 \text {-min, able to communicate } \\
\text { with investigators }\end{array}$ & $\begin{array}{l}\text { Significant improvement in } \\
\text { peak AGRF with } \\
\text { biofeedback condition. }\end{array}$ \\
\hline Ma et al. (8) & Kinetic & Haptic & Chronic & $\begin{array}{l}\text { Ambulation with } \\
\text { Biofeedback turned off. } \\
\text { Repeated measures design }\end{array}$ & $\begin{array}{l}\text { Able to ambulate } 10 \mathrm{~m} \\
\text { independently }\end{array}$ & $\begin{array}{l}\text { Significant reduction in foot } \\
\text { inversion with biofeedback } \\
\text { condition. }\end{array}$ \\
\hline $\begin{array}{l}\text { Wolf and } \\
\text { Binder-MacLeod (31) }\end{array}$ & EMG & $\begin{array}{l}\text { Visual and } \\
\text { Auditory }\end{array}$ & Chronic & $\begin{array}{l}\text { Three other groups: No } \\
\text { biofeedback, general } \\
\text { relaxation, upper extremity } \\
\text { biofeedback }\end{array}$ & $\begin{array}{l}\text { No previous exposure to } \\
\text { EMG biofeedback }\end{array}$ & $\begin{array}{l}\text { Experimental group did not } \\
\text { experience significant } \\
\text { increase in walking speed, } \\
\text { but did reduce dependence } \\
\text { on assistive devices. }\end{array}$ \\
\hline
\end{tabular}

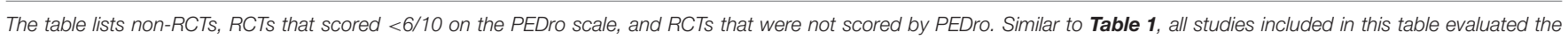

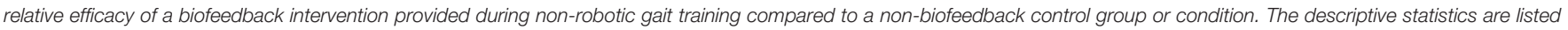
as average (standard deviation).

for providing biofeedback during post-stroke gait retraining, our inclusion criteria that relate to quality and study design are broader, including both RCTs and non-RCTs, with the intent of evaluating a greater number of studies Tables 1 and 2. Our overall goal was to determine whether gait biofeedback is effective at improving stroke gait deficits while also probing why and for whom gait biofeedback may be an efficacious treatment modality. We first identify, categorize, and summarize factors impacting the results of previous research related to post-stroke gait biofeedback.

\section{TYPES OF GAIT BIOFEEDBACK Target Parameters During Gait Biofeedback}

Previously, Tate and Milner (2) identified the four most prevalent biofeedback target parameters for gait training: (1) EMG biofeedback, which targets magnitude of activation in a specific muscle; (2) kinematic biofeedback, which targets segment motions or joint angles during specific phases of the gait cycle (e.g., hip, knee, or ankle angles during swing phase); (3) kinetic biofeedback, which targets forces generated during a phase of gait (e.g., push-off force or downward pressure exerted on an assistive device during the stance phase of gait); and (4) spatiotemporal biofeedback, which relates to the spatial and temporal aspects of gait (e.g., step length, cadence) (Figure 1A). Of the 4 forms of gait biofeedback, EMG biofeedback may be the most well-researched in post-stroke individuals, with individual
RCTs demonstrating mixed results $(14,23,30-32)$. One possible explanation for the unremarkable results from EMG biofeedback studies may be the focality of the treatment target. Because EMG biofeedback only targets one muscle group at a time (usually the triceps surae), this treatment may provide the greatest benefit to individuals whose gait deficits are largely impacted by functional weakness in a single muscle group and have adequate residual strength to perform a volitional contraction. This approach often neglects the importance of retraining other hemiparetic muscle groups, such as the quadriceps or hamstrings. As a result, participant inclusion and exclusion criteria, which are not uniform across these studies, likely have a significant influence on treatment success (33). Another possible explanation for variable effects of EMG biofeedback lies in the fact that while having been in existence for decades, the technologies and protocols underlying EMG biofeedback may have evolved and contributed additional variability in study methods and research results (14, $23,31,34)$.

There are fewer studies from which conclusions can be drawn using other forms of gait biofeedback. Morris et al. (24) and Basaglia et al. (35) both found that electrogoniometric biofeedback (a form of kinematic biofeedback) significantly reduced genu recurvatum in post-stroke individuals, but little additional research has been done on the topic. Spatiotemporal biofeedback that targets paretic step length or step width has yielded inconsistent results in people post-stroke $(4,21$, 36). A recent high-quality randomized control trial performed by Druzbicki et al. (21) failed to demonstrate significant 
improvements in gait quality following step length biofeedback compared to conventional treadmill training. Importantly, Druzbicki et al.'s (21) study differed from many other biofeedback RCTs by involving patients in the sub-acute phase of recovery and combined biofeedback with body weight supported gait training. The same study team also performed another highquality RCT using similar feedback parameters (visual feedback targeting paretic step length during treadmill training) on individuals with chronic stroke, and found no significant longterm increases in step length and step symmetry compared to a control group of post-stroke individuals performing treadmill training without biofeedback when initial values were compared to those gathered after 6-month $(22,36)$. Similarly, Brasileiro et al. (25) found no significant improvement in stride length in post stroke individuals with the addition of spatiotemporal biofeedback to partial bodyweight supported treadmill training program. Biofeedback targeting step-width is less prevalent as a gait training modality for individuals post-stroke (29).

Kinetic biofeedback most commonly involves the use of force sensors placed either in the shoe or embedded within the surface over which the individual is ambulating, such as the floor or a treadmill. Sungkarat et al. (26) and a pilot study by Choi et al. (20) both used forms of kinetic biofeedback to retrain increased paretic leg weight bearing following stroke, with the former finding a significant increase in gait symmetry compared to the non-biofeedback control, and the latter finding significant improvements in the 10-meter walk test, functional gait assessment, and center of pressure path length relative to the non-biofeedback control. Jung et al. (27) employed a unique version of kinetic biofeedback in the form of a pressure sensing cane which provided auditory cues designed to reduce assistive device dependence in post-stroke individuals. Following 4 weeks of training, participants in the experimental group experienced significant improvements in both peak force through assistive device and in gait speed compared to the control group (27). Anterior ground reaction force (AGRF) biofeedback is another form of kinetic feedback which encourages greater push-off from the paretic leg (37), which in turn enables effective transition from the stance to swing phase of gait and faster gait speeds (1). Unlike EMG feedback targeting a single muscle (e.g., triceps surae), AGRF biofeedback targets force production from and orientation of the paretic limb as a whole, encouraging activation of multiple muscle groups involved in generating push off (1). Preliminary literature on AGRF gait biofeedback is promising, showing improvements in AGRF and propulsion-related variables only in the targeted (paretic) leg, albeit from a single-session smallsample study (1). There is also evidence that AGRF biofeedback can improve push off force in older adults who are not affected by stroke (38).

In summary, a review of previous biofeedback studies reveals that multiple target gait parameters have been utilized with the goal of improving post-stroke gait impairments with mixed results. Several additional methodological factors discussed in subsequent subsections can impact the efficacy of gait biofeedback.

\section{Modes of Feedback}

During gait training, biofeedback output can be provided using auditory cues, a visual display interface, tactile stimuli, or a combination of multiple modes (Figure 1A). Auditory signals $(1,23)$ and visual displays $(1,21)$ are the two most commonly used means of conveying feedback to the patient, but other feedback modes have also been explored. Haptic biofeedback, presented as vibratory or tactile sensory stimuli delivered via surface electrodes, has been studied in conjunction with wearable plantar force sensors $(8,39)$. Additionally, virtual reality (VR) gait training, which constitutes an immersive 3-dimensional interface in which patients can perform real world activities (40), can be sub-categorized as a visual gait biofeedback mode if the VR involves integration of real-time gait performance data. A notable form of VR gait training is optic flow, which renders an artificial virtual environment which fails to match proprioceptive input in order to facilitate correction of gait abnormalities (41). Kang et al. (41) found that treadmill training with modulated optic flow resulted in significantly improved gait velocity compared to standard treadmill training. A recent systematic review concluded that VR-based training is more effective than balance or gait training without VR at improving balance and gait ability following stroke (40). However, the studies included in this review demonstrated considerable variability in both content and quality, likely because VR-based gait interventions are still in early developmental stages (40-43).

Only a few studies compare different modes of feedback in post-stroke individuals. A study (44) involving only nine poststroke and seven able bodied individuals found no significant differences in AGRF in the post-stroke group during gait trials comprising visual, audiovisual, and auditory biofeedback but acknowledged that more systematic larger-sample investigations are needed to determine the most optimal feedback mode. Additionally, because visual and sensory deficits are common following stroke, clinicians must consider how each stroke survivor's deficits may interfere with processing a particular biofeedback mode $(45,46)$. For example, proprioceptive or visual field deficits may interfere with a stroke survivor's ability to capitalize on haptic or visual feedback cues, respectively. The training environment is another factor to consider when selecting the mode of feedback. For example, a user on a treadmill in a clinical setting may be an appropriate candidate for visual modes of biofeedback while a stroke survivor ambulating overground or unsupervised in the community may be a better candidate for auditory feedback delivered via a headset connected to their smart phone. Finally, the feedback mode may impact motor learning processes. Visual feedback may be more likely to create dependence on external cues than auditory feedback, as individuals who received concurrent visual feedback demonstrated worse performance on motor skill retention tests than those receiving auditory feedback $(47,48)$.

Another important factor in selecting a feedback mode is the coding scheme (i.e., the method by which the magnitude of error in ongoing task performance is processed and conveyed to the patient during biofeedback). In repeated measures study $(n=8)$, Afzal et al. (49) applied vibrotactile feedback to 
post-stroke individuals during ambulation training with the intention of correcting gait asymmetry. Feedback regarding the magnitude of ongoing error in inter-limb step length asymmetry was provided to study participants but using different mechanisms to code or transform the ongoing error in gait performance to vibrotactile feedback. Either the duration or frequency of vibrotactile feedback was modulated, using either positive or negative encoding. Thus, in addition to a bout of ambulation without feedback (control), each participant completed trials of overground ambulation while receiving biofeedback provided with each of the following vibrotactile coding schemes: (i) duration of vibration feedback increases proportionally with the magnitude of error, (ii) vibration duration is inversely related to error magnitude, (iii) vibration intensity increases proportionately with error magnitude, and (iv) vibration intensity is inversely related to error magnitude. Despite the small sample size, Afzal et al. found a significant effect of the type of vibratory feedback coding schemes on gait symmetry ratio. Interestingly, a significant improvement in gait symmetry ratio was observed during proportional feedback coding provided by varying vibration duration compared to vibration intensity (49), suggesting that, at least for vibrotactile or haptic modes of feedback, modulating the duration vs. the intensity of vibration duration coding may yield more favorable results. However, there is a need to evaluate these results in larger sample studies and using other forms of feedback (e.g., auditory). Studies comparing time-coded and intensity-coded biofeedback schemes to non-magnitude coded biofeedback that provides the same biofeedback signal type regardless of error size should also be undertaken. Feedback strategies of coding schemes, particularly duration-based coding of error magnitude may lead to superior motor learning compared to uniform error signals in patients who are able to process more complex signals as the former provides the patient with more information regarding aberrant movement patterns, but more confirmatory studies are needed.

The combination of a primary mode of feedback with a secondary feedback target intervention has been studied recently. Shin et al. (50) found that the addition of a rhythmic auditory cue to visual biofeedback led to a significant improvement in symmetry ratio compared to both visual biofeedback alone and non-biofeedback controls. Cherry-Allen et al. (51) simultaneously explicitly targeted knee joint angle via visual biofeedback and step length asymmetry implicitly via split belt walking, and found similar joint angle changes in response to both the biofeedback plus split-belt treadmill group and the biofeedback only group, indicating that individuals with stroke have the capacity to target two deficits concurrently in the same session. Afzal et al. (28) showed that combined use of a haptic cane device providing kinesthetic perception and a vibrotactile device providing tactile cues on the paretic leg increased gait speed and symmetry post-stroke. The combination system incorporated input from wireless EMG sensors and smartphone measurements of trunk sway to target suboptimal gait patterns (28). These recent studies on relatively small, homogenous samples, suggest that more research is needed for an optimal individual-specific selection of multiple biofeedback targets or for combining biofeedback with a second intervention. There is also little research surrounding the effect of combining gait biofeedback with modalities, such as motor priming (52) or non-invasive neuromodulation techniques [e.g., transcranial direct current stimulation $(53,54)$, repetitive transcranial magnetic stimulation (55)], on the efficacy of gait biofeedback. Additionally, the feasibility of applying more complex biofeedback protocols in clinical settings requires considerable exploration before defining algorithms that can be followed successfully.

\section{KEY METHODOLOGICAL FACTORS INFLUENCING RESPONSE TO GAIT BIOFEEDBACK}

\section{Practice Structure and Feedback Schedule During Gait Training}

Careful manipulation of the structure of practice within a training session (e.g., how bouts of biofeedback gait training are organized within a session) and feedback schedule (how frequently biofeedback input is provided to the individual during and across training bouts) are important factors impacting the magnitude of locomotor learning (47); yet few previous efforts have incorporated strategies to enhance motor learning during the use of biofeedback for retraining stroke gait (4) (Figure 1B). Jonsdottir et al. (23) conducted an RCT that incorporated principles of motor learning during EMG biofeedback by using variable practice and a faded feedback schedule, and found significant increases in push off, gait velocity, and step length in the biofeedback group and no significant improvements in the control group, both immediately post-treatment and 6 weeks following treatment. However, because the gait training received by the control group consisted of strategies selected by clinicians at the rehabilitation center, the exact nature of which were not directly specified, the larger improvement in the experimental group could be due to variable practice gait training (changes in gait speed, direction, terrain and step length which may not have been a component of the control intervention) with the addition of biofeedback being potentially inconsequential (23). While there appears to be no RCT directly comparing practice structure or feedback schedules between two gait biofeedback training groups, Tsaih et al. (56) did compare variable and constant practice during biofeedback-based balance training and found that the group receiving variable force biofeedback to the tibialis anterior displayed better standing balance than the group receiving constant force biofeedback. While these studies alone cannot definitively prove that variable practice biofeedback gait training is superior to constant practice biofeedback gait training, their results underscore the need for further investigation $(23,56)$. Similarly, other potential permutations of practice parameters or feedback structure, such as massed and spaced practice schedules should be evaluated using one or more forms of biofeedback. Finally, the relative success of the Jonsdottir et al. study compared to other EMG biofeedback RCTs suggests that mode of feedback may be less important than other aspects of experiment design. 


\section{Dosing}

There is little research evaluating the effect of dosage on gait biofeedback training. In fact, "dose" is often an ill-defined a term in stroke rehabilitation studies (47). Here, dosing includes feedback duration (amount of time spent on biofeedback gait training during each session), training frequency (e.g., how often the biofeedback sessions occurred per week), and total number of treatment sessions (e.g., 3 vs. 18 training sessions). Many gait biofeedback studies for post stroke individuals only evaluated changes in gait variables in response to a single session of training, while multi-session studies displayed variability in the number of sessions and duration of practice per session $(1,23,36)$. In general, multi-session studies comprised 10-20 sessions $(1,23,24,29,30,36)$, with each session being 11$30 \mathrm{~min}$ in duration. Treatment frequency varied from three times per week to twice per day $(21,29,30,37)$. There is insufficient evidence to comment on the relative efficacy of different dosing strategies or the optimal recommended dosage, a phenomenon not unique to biofeedback gait training. While some research findings indicates that increased therapy time may lead to improved outcomes in post-stroke individuals (47), the exact nature of the dose-response relationship for physical therapy and motor recovery following stroke is a broad area that requires further investigation (47). Dose response characteristics of physical therapy treatments, such as gait biofeedback poststroke, may also be influenced by chronicity of stroke, and vary across the stages of recovery (47).

\section{Participant Selection Criteria}

Bernhardt et al. outlined the chronological stages of stroke recovery from a rehabilitation perspective as follows: hyper acute ( $0-24 \mathrm{~h})$, acute ( $1-7$ days), early subacute ( 7 days to 3 months), late subacute (3-6 months), and chronic ( $>6$ months) (57). The majority of high quality biofeedback research has been conducted on individuals in the chronic and late subacute stages of stroke rehabilitation $(2,4,14)$. There is a scarcity of RCTs in the early recovery stages for post-stroke motor interventions (58), a phenomenon that remains true for biofeedback studies. A recent high-quality biofeedback study in the early subacute period $(<30$ days post-stroke) was performed by Druzbicki et al. (21), but improvements in step symmetry index between the biofeedback and control groups were not statistically significant. However, this study uniquely differed from many other biofeedback RCTs by providing step length biofeedback during bodyweight supported treadmill walking. Overall, there is little research comparing the efficacy of biofeedback interventions for patients in different stages of recovery.

The severity of sensorimotor deficits of stroke participants is another source of variability between studies (Figure 1C). Because there is no strong evidence outlining the clinical characteristics of responders and non-responders to gait biofeedback, inclusion and exclusion criteria tend to differ widely across studies. However, most stroke studies consider cognition, level of gross motor deficit, and level of visual deficit when selecting patients. Exclusion criteria for cognitive deficits have the highest degree of uniformity, with several studies setting a mini-mental state exam score cutoff at 24 for inclusion (21-23).
However, other studies fail to include measures of mental acuity in their patient selection process (1). Possibly, a mini-mental cutoff of 24 is conservative for the purposes of generating clean data, and more research should be undertaken to evaluate the relative efficacy of these interventions on individuals with lower mini-mental scores, given that cognitive deficits are common post-stroke (59). Estimates of the prevalence of cognitive deficits following stroke vary, but a large scale study using data from 10 countries found that about 30\% of individuals with ischemic stroke had cognitive deficits (mini-mental score $<27$ ) (59). Biofeedback interventions may be particularly effective for people whose internal feedback systems are compromised, including those with proprioceptive deficits, as the biofeedback would serve as a substitute for the reduced peripheral input (17). There is also evidence suggesting that perceptual deficits contribute to gait asymmetry in post-stroke individuals, a problem that could be addressed by augmenting sensory input to improve awareness (60). In a study on able-bodied individuals, vibratory stimuli were delivered to targeted muscles (gluteus medius) during gait (stance and swing) to evoke artificial proprioceptive feedback, with promising effects on frontal plane motion during gait (61). However, we could not find studies probing the relationship between sensory impairments poststroke and response to biofeedback or implementing augmented proprioceptive feedback to retrain post-stroke gait, pointing to another future research area. Overall lower extremity motor deficit is another patient selection criterion, but the measurement tools and cutoff points used to quantify level of deficit vary widely $(1,8,23)$. Past studies have included stroke survivors at a specific Brunnstrom stage of recovery $(21,22)$ or with ability to ambulate a predetermined distance or time $(1,23,24)$.

\section{SUMMARY OF GAPS IN PREVIOUS RESEARCH}

Due to the varied and often conflicting nature of evidence, more research is needed to prove the efficacy of gait biofeedback for post-stroke individuals $(2,4)$. However, without a concerted effort to explore the underlying mechanisms that impact the success of gait biofeedback interventions on poststroke individuals, inconsistent results will likely continue to be observed. Future studies should be designed to directly compare various biofeedback parameters such as feedback target, mode, dosage, etc. in individuals with varied sensorimotor impairments post-stroke.

Our review of previous literature provides several indications of where to begin such future investigations. First, modes of feedback and target parameters could be compared directly across multiple patient populations. Second, motor learning strategies, such as faded feedback or variable practice structure, could be tested against more conventional procedures for the application of biofeedback. Third, greater efforts should be made to identify characteristics of responders and nonresponders. Fourth, studies aimed at evaluating dose-response relationships are needed. Fifth, large-sample RCTs are needed, especially for stroke survivors in more acute stages of recovery 
to compare the relative efficacy of biofeedback for different stages of recovery.

\section{Neurophysiological and Motor Learning Mechanisms Underlying Gait Biofeedback}

As is true for a majority of neuro-rehabilitation treatments, the efficacy of biofeedback as a gait training intervention stands to benefit from a better understanding of the underlying neurophysiological, biomechanical, and motor learning mechanisms of gait biofeedback. There is a research gap related to short-term and long-term changes in cortical and spinal circuitry following gait biofeedback interventions. As an illustration of a study exploring both the biomechanical and neural processes of gait biofeedback, Pietrosimone et al. (62) demonstrated that the use of EMG biofeedback during an isometric force generation task significantly increased both peak knee extension torque and amplitudes of motor evoked potentials elicited from the quadriceps muscles in response to transcranial magnetic stimulation in able bodied individuals (62). The authors argued that these results indicate EMG biofeedback may be a viable strategy for enhancing corticomotor excitability (62). More similar research is needed. The extent to which similar modulation of corticospinal excitability can be achieved during ambulation, with post-stroke individuals, or with other modes of biofeedback remains unknown (63). These gaps in knowledge regarding how and why biofeedback induces its effects on post-stroke gait constitute necessary steps toward developing evidence-based gait biofeedback protocols.

\section{PERSPECTIVES FOR FUTURE RESEARCH DIRECTIONS RELATED TO GAIT BIOFEEDBACK}

Based on the review of previous research, our long-term vision is that cumulative evidence derived from a series of mechanismfocused and translational gait feedback studies will facilitate the development of clinical prediction rules or decision-making guidelines for more effective and individualized rehabilitation of post-stroke walking function. Completing the studies needed to systematically and individually delineate the multiple variables affecting the success of biofeedback gait training may be time consuming, but the efforts involved would be outweighed by the potential reward of one or more highly effective biofeedback interventions that can later leverage novel wearable sensor technologies.

\section{Emerging Wearable Sensor Technologies for Gait Biofeedback}

Over the past decade, technological evolutions have highlighted novel biofeedback applications to enhance the effectiveness, broaden the application, and advance the clinical impact of gait biofeedback. Wearable sensors can allow a stroke survivor to receive biofeedback via portable, non-obtrusive, non-restrictive, user-friendly sensor units on their person, enabling decrease in the cost and increase in the usability of gait biofeedback (64). Many newly developed wearable sensor devices can track gait parameters in real-time, a process which previously required expensive, traditional, laboratory-based biofeedback systems. Recent research efforts have evaluated the validity and reliability of gait outcomes derived from wearable sensors, although more rigorous evaluations of the measurement properties and biofeedback applications of wearable sensors are needed $(64,65)$. Wearable sensing systems can accurately measure joint angle information during ambulation (17). Kinematic data can be recorded by wearable gyroscopes which measure changes in angular momentum, wearable accelerometers which measure the rate at which a body segment changes speed, and wearable magnetometers capable of capturing a body part's orientation relative to gravity (64). Kinetic variables can be reliably tracked through sensors, such as force sensing in-shoe insoles, or pressure sensing assistive devices $(27,66)$. Additionally, multiple types of measurement sensors can be combined into a single wearable device to increase overall utility and scope of biofeedback (64). Sensors, such as accelerometers and gyroscopes, have also been used to provide spatiotemporal feedback (67). Similarly, wearable, wireless EMG sensors and EMG biofeedback systems are available (68). Modes of feedback can be user-friendly, and provide cues regarding ongoing gait patterns to the user via vibratory or tactile cues emitted from small devices worn by or attached to the patient, or a smartphone (64).

\section{Promising Clinical Applications of Gait Biofeedback for Home-Based and Tele-Rehabilitation}

The accessibility and ease-of-use of new wearable sensorbased gait biofeedback systems may make biofeedback gait training more readily available across diverse practice settings (69, 70). Potentially, a single clinical facility could have a "biofeedback toolbox" with multiple options from which to choose, allowing clinicians to tailor the feedback mode, target, and method that best matches each patient's baseline clinical profile. Wearable sensors can also be compatible with use at home and in community settings (70), enabling high-quality stepping practice outside of the clinic, using customized gait target parameters prescribed by the clinician during in-clinic or tele-rehabilitation evaluations. Considering the established role of repetitive stepping practice in promoting motor recovery, gait biofeedback could become a pivotal addition to a home exercise program for post-stroke individuals (71). The ability to provide skilled, clinician-selected cues without the constant physical presence of a clinician could also have major ramifications for tele-medicine. Cramer et al. (72) found a novel upper extremity telehealth protocol to be non-inferior to in-person therapy for post-stroke individuals, but no lower extremity counterpart exists. Biofeedback can certainly be an important component of tele-rehabilitation treatment protocols, aiding with both retraining of gait quality and remote evaluation of performance, as data gathered through home-based gait biofeedback devices is transmitted from the home to the clinic.

Compared to upper extremity rehabilitation, a telerehabilitation system specifically designed for lower extremity or gait biofeedback training would present a series of 
unique challenges and safety considerations. Ensuring safe implementation would be the foremost concern for both telehealth and conventional home exercise gait biofeedback interventions. Unlike upper limb retraining, gait training requires provision for adequate guarding to prevent falls and injuries during home-exercises. Involvement of the caregiver or supervision from the clinician via tele-rehabilitation may help enhance safety and feasibility. Thus, considerable thought and attention will be needed to ensure a suitable environment for gait biofeedback, and to select patients with low fall risk, or with capacity to ambulate short distances without assistance.

Dorsch et al. (73) conducted a large-scale trial in which wearable sensors were used to monitor functional gait variables including walking speed and total walking time in post-stroke individuals, but this study was completed in the inpatient rehabilitation setting, and did not involve the use of real-time biomechanical feedback to improve gait quality. There is a need for more studies assessing the efficacy of wearable sensorbased gait interventions. One systematic review (74) found that incorporation of wearable sensors into gait and balance training had a positive training effect compared to usual care and balance training controls; however, only a few heterogeneous RCTs specifically targeted gait and stroke (74). While the results are promising, more RCTs assessing the efficacy of biofeedback provided via wearable sensors especially in community settings are needed.

Finally, there is limited research evaluating the efficacy of gait biofeedback without the presence of a neurorehabilitation clinician or with remote supervision by a clinician. If home-based stepping exercises with gait biofeedback are shown to be safe and at least as effective as home-based walking practice without feedback, gait biofeedback could transform rehabilitation by enhancing patient compliance with home exercise programs, accurately tracking progress and gait performance during community ambulation, and retraining both gait quality and gait speed beyond the clinical therapy sessions. More importantly, biofeedback employed in home-settings may prove to be markedly more effective at promoting neuroplasticity and restoring function than traditional home-exercise programs, due to its ability to enable more precise and higher quality of repetitive stepping practice.

\section{CONCLUSIONS}

The current evidence regarding the effectiveness of gait biofeedback following stroke is equivocal, but positive trends indicate promise. Our literature review summarized factors

\section{REFERENCES}

1. Genthe K, Schenck C, Eicholtz S, Zajac-Cox L, Wolf S, Kesar TM. Effects of real-time gait biofeedback on paretic propulsion and gait biomechanics in individuals post-stroke. Top Stroke Rehabil. (2018) 25:186-93. doi: 10.1080/10749357.2018.1436384

2. Stanton R, Ada L, Dean CM, Preston E. Biofeedback improves performance in lower limb activities more than usual therapy in contributing to variability in the results of past studies, such as different types of feedback targets (kinematic, kinetic, spatiotemporal, and EMG), feedback modes (visual, auditory, and haptic), practice structure, dosage, and patient characteristics. Based on our analyses of the gaps in the previous research, we suggest that more favorable and conclusive evidence supporting gait biofeedback can be achieved if larger-sample studies are conducted to directly compare different feedback parameters, employ more uniformity in experimental design, and evaluate patient characteristics of potential responders. The cumulative research evidence gained from an amalgam of mechanism-focused and clinical research will yield clinical prediction rules and decision-making algorithms for optimization of gait biofeedback parameters. Wearable sensor technologies have the potential to transform gait biofeedback and provide greater access and wider array of options for the clinicians while lowering costs. Sensing technologies will be particularly valuable for telehealth and home-based stepping exercise programs. High-quality, portable, user-friendly gait biofeedback systems will provide patients with clinician-determined cues regarding gait performance resulting in a greater number of high-quality repetitions during walking practice. In summary, gait biofeedback has strong potential as a post-stroke gait training tool and warrants further research.

\section{AUTHOR CONTRIBUTIONS}

JS developed the manuscript draft, conducted the review of literature, and summarized the findings of the review. SW was involved in editing and finalizing the manuscript. TK assisted JS with the literature review, conceptualized the study, and was involved with editing and finalizing the manuscript. All authors contributed to the article and approved the submitted version.

\section{FUNDING}

TK was supported by NIH NICHD grant awards R01 HD095975 and R21 HD095138. SW was supported from these awards and grant 1U10NS086607.

\section{ACKNOWLEDGMENTS}

We thank informationist Sharon Leslie, MSLS, AHIP., librarian at the Emory University for her assistance with the literature database searches; Dr. Shilpa Krishnan for consulting on the conceptualization and planning of the literature review and manuscript. 
5. Wolf SL. Essential considerations in the use of EMG biofeedback. Phys Ther. (1978) 58:25-31. doi: 10.1093/ptj/58.1.25

6. Baker M, Regenos E, Wolf SL, Basmajian JV. Developing strategies for biofeedback. Applications in neurologically handicapped patients. Phys Ther. (1977) 57:402-8. doi: 10.1093/ptj/57.4.402

7. Barcala L, Grecco LA, Colella F, Lucareli PR, Salgado AS, Oliveira CS. Visual biofeedback balance training using wii fit after stroke: a randomized controlled trial. J Phys Ther Sci. (2013) 25:1027-32. doi: 10.1589/jpts.25.1027

8. Ma CZ, Zheng YP, Lee WC. Changes in gait and plantar foot loading upon using vibrotactile wearable biofeedback system in patients with stroke. Top Stroke Rehabil. (2018) 25:20-7. doi: 10.1080/10749357.2017.1380339

9. Hollands KL, Pelton TA, Tyson SF, Hollands MA, van Vliet PM. Interventions for coordination of walking following stroke: systematic review. Gait Posture. (2012) 35:349-59. doi: 10.1016/j.gaitpost.2011.10.355

10. Nadeau S, Betschart M, Bethoux F. Gait analysis for poststroke rehabilitation: the relevance of biomechanical analysis and the impact of gait speed. Phys Med Rehabil Clin N Am. (2013) 24:265-76. doi: 10.1016/j.pmr.2012.11.007

11. Harris-Love ML, Forrester LW, Macko RF, Silver KH, Smith GV. Hemiparetic gait parameters in overground versus treadmill walking. Neurorehabilitation Neural Repair. (2001) 15:105-12. doi: 10.1177/154596830101500204

12. Benjamin EJ, Blaha MJ, Chiuve SE, Cushman M, Das SR, Deo $\mathrm{R}$, et al. Heart disease and stroke statistics-2017 update: a report from the American Heart Association. Circulation. (2017) 135:e146-603. doi: 10.1161/CIR.0000000000000491

13. Langhorne P, Coupar F, Pollock A. Motor recovery after stroke: a systematic review. Lancet Neurol. (2009) 8:741-54. doi: 10.1016/S1474-4422(09)70150-4

14. Woodford H, Price C. EMG biofeedback for the recovery of motor function after stroke. Cochrane Database Syst Rev. (2007) 2:CD004585. doi: 10.1002/14651858.CD004585.pub2

15. French B, Thomas LH, Coupe J, McMahon NE, Connell L, Harrison J, et al. Repetitive task training for improving functional ability after stroke. Cochrane Database Syst Rev. (2016) 11:Cd006073. doi: 10.1002/14651858.CD006073.pub3

16. Hornby TG, Reisman DS, Ward IG, Scheets PL, Miller A, Haddad D, et al. Clinical practice guideline to improve locomotor function following chronic stroke, incomplete spinal cord injury, and brain injury. J Neurol Phys Ther. (2020) 44:49-100. doi: 10.1097/NPT.0000000000000303

17. Horak F, King L, Mancini M. Role of body-worn movement monitor technology for balance and gait rehabilitation. Phys Ther. (2015) 95:46170. doi: 10.2522/ptj.20140253

18. van Gelder LMA, Barnes A, Wheat JS, Heller BW. The use of biofeedback for gait retraining: a mapping review. Clin Biomech.(2018) 59:15966. doi: 10.1016/j.clinbiomech.2018.09.020

19. Semrau JA, Herter TM, Scott SH, Dukelow SP. Examining differences in patterns of sensory and motor recovery after stroke with robotics. Stroke. (2015) 46:3459-69. doi: 10.1161/STROKEAHA.115.0 10750

20. Choi YH, Kim JD, Lee JH, Cha YJ. Walking and balance ability gain from two types of gait intervention in adult patients with chronic hemiplegic stroke: a pilot study. Assist Technol. (2019) 31:112-5. doi: 10.1080/10400435.2017.1387616

21. Druzbicki M, Przysada G, Guzik A, Brzozowska-Magon A, Kolodziej $\mathrm{K}$, Wolan-Nieroda A, et al. The efficacy of gait training using a body weight support treadmill and visual biofeedback in patients with subacute stroke: a randomized controlled trial. Biomed Res Int. (2018) 2018:3812602. doi: 10.1155/2018/3812602

22. Druzbicki M, Guzik A, Przysada G, Kwolek A, Brzozowska-Magon A, Sobolewski M. Changes in gait symmetry after training on a treadmill with biofeedback in chronic stroke patients: a 6-month followup from a randomized controlled trial. Med Sci Monit. (2016) 22:485968. doi: 10.12659/MSM.898420

23. Jonsdottir J, Cattaneo D, Recalcati M, Regola A, Rabuffetti M, Ferrarin M, et al. Task-oriented biofeedback to improve gait in individuals with chronic stroke: motor learning approach. Neurorehabilitation Neural Repair. (2010) 24:478-85. doi: 10.1177/1545968309355986

24. Morris ME, Matyas TA, Bach TM, Goldie PA. Electrogoniometric feedback: its effect on genu recurvatum in stroke. Arch Phys Med Rehabil. (1992) 73:1147-54. PubMed PMID: 1463378.
25. Brasileiro A, Gama G, Trigueiro L, Ribeiro T, Silva E, Galvao E, et al. Influence of visual and auditory biofeedback on partial body weight support treadmill training of individuals with chronic hemiparesis: a randomized controlled clinical trial. Eur J Phys Rehabil Med. (2015) 51:49-58.

26. Sungkarat S, Fisher BE, Kovindha A. Efficacy of an insole shoe wedge and augmented pressure sensor for gait training in individuals with stroke: a randomized controlled trial. Clin Rehabil. (2011) 25:3609. doi: 10.1177/0269215510386125

27. Jung K, Kim Y, Cha Y, In TS, Hur YG, Chung Y. Effects of gait training with a cane and an augmented pressure sensor for enhancement of weight bearing over the affected lower limb in patients with stroke: a randomized controlled pilot study. Clin Rehabil. (2015) 29:135-42. doi: 10.1177/0269215514540923

28. Afzal MR, Pyo S, Oh MK, Park YS, Yoon J. Evaluating the effects of delivering integrated kinesthetic and tactile cues to individuals with unilateral hemiparetic stroke during overground walking. J Neuroeng Rehabil. (2018) 15:33. doi: 10.1186/s12984-018-0372-0

29. Aruin AS, Hanke TA, Sharma A. Base of support feedback in gait rehabilitation. Int $J$ Rehabil Res. (2003) 26:30912. doi: 10.1097/01.mrr.0000102059.48781.a8

30. Bradley L, Hart BB, Mandana S, Flowers K, Riches M, Sanderson P. Electromyographic biofeedback for gait training after stroke. Clin Rehabil. (1998) 12:11-22. doi: 10.1191/026921598677671932

31. Wolf SL, Binder-MacLeod SA. Electromyographic biofeedback applications to the hemiplegic patient. Changes in lower extremity neuromuscular and functional status. Phys Ther. (1983) 63:1404-13. PubMed PMID: 6611661. doi: 10.1093/ptj/63.9.1404

32. Moreland JD, Thomson MA, Fuoco AR. Electromyographic biofeedback to improve lower extremity function after stroke: a meta-analysis. Arch Phys Med Rehabil. (1998) 79:134-40. doi: 10.1016/S0003-9993(98)90289-1

33. Schleenbaker RE, Mainous AG 3rd. Electromyographic biofeedback for neuromuscular reeducation in the hemiplegic stroke patient: a meta-analysis. Arch Phys Med Rehabil. (1993) 74:13014. doi: 10.1016/0003-9993(93)90083-M

34. Tamburella F, Moreno JC, Herrera Valenzuela DS, Pisotta I, Iosa M, Cincotti $\mathrm{F}$, et al. Influences of the biofeedback content on robotic post-stroke gait rehabilitation: electromyographic vs. joint torque biofeedback. J Neuroeng Rehabil. (2019) 16:95. doi: 10.1186/s12984-019-0558-0

35. Basaglia N, Mazzini N, Boldrini P, Bacciglieri P, Contenti E, Ferraresi G. Biofeedback treatment of genu-recurvatum using an electrogoniometric device with an acoustic signal. One-year follow-up. Scand J Rehabil Med. (1989) 21:125-30. PubMed PMID: 2799310.

36. Druzbicki M, Guzik A, Przysada G, Kwolek A, Brzozowska-Magon A. Efficacy of gait training using a treadmill with and without visual biofeedback in patients after stroke: a randomized study. J Rehabil Med. (2015) 47:41925. doi: 10.2340/16501977-1949

37. Schenck C, Kesar TM. Effects of unilateral real-time biofeedback on propulsive forces during gait. J Neuroeng Rehabil. (2017) 14:52. doi: 10.1186/s12984-017-0252-Z

38. Franz JR, Maletis M, Kram R. Real-time feedback enhances forward propulsion during walking in old adults. Clin Biomech. (2014) 29:6874. doi: 10.1016/j.clinbiomech.2013.10.018

39. Schenck C, Bakke D, Besier T. Haptic biofeedback induces changes in ankle push-off during walking. Gait Posture. (2019) 74:76-82. doi: 10.1016/j.gaitpost.2019.07.252

40. de Rooij IJ, van de Port IG, Meijer JG. Effect of virtual reality training on balance and gait ability in patients with stroke: systematic review and meta-analysis. Phys Ther. (2016) 96:1905-18. doi: 10.2522/ptj.20160054

41. Kang HK, Kim Y, Chung Y, Hwang S. Effects of treadmill training with optic flow on balance and gait in individuals following stroke: randomized controlled trials. Clin Rehabil. (2012) 26:246-55. doi: 10.1177/0269215511419383

42. Kim N, Park Y, Lee BH. Effects of community-based virtual reality treadmill training on balance ability in patients with chronic stroke. J Phys Ther Sci. (2015) 27:655-8. doi: 10.1589/jpts.27.655

43. Hung JW, Chou CX, Hsieh YW, Wu WC, Yu MY, Chen PC, et al. Randomized comparison trial of balance training by using exergaming and conventional weight-shift therapy in patients with chronic stroke. Arch Phys Med Rehabil. (2014) 95:1629-37. doi: 10.1016/j.apmr.2014.04.029 
44. Liu J, Kim HB, Wolf SL, Kesar TM. Comparison of the immediate effects of audio, visual, or audiovisual gait biofeedback on propulsive force generation in able-bodied and post-stroke individuals. Appl Psychophysiol Biofeedback. (2020) 45:211-20. doi: 10.1007/s10484-020-09464-1

45. Pula JH, Yuen CA. Eyes and stroke: the visual aspects of cerebrovascular disease. Stroke Vasc Neurol. (2017) 2:210-20. doi: 10.1136/svn-2017-000079

46. Kessner SS, Bingel U, Thomalla G. Somatosensory deficits after stroke: a scoping review. Top Stroke Rehabil. (2016) 23:13646. doi: 10.1080/10749357.2015.1116822

47. Maier M, Ballester BR, Verschure P. Principles of neurorehabilitation after stroke based on motor learning and brain plasticity mechanisms. Front Syst Neurosci. (2019) 13:74. doi: 10.3389/fnsys.2019.00074

48. Ronsse R, Puttemans V, Coxon JP, Goble DJ, Wagemans J, Wenderoth $\mathrm{N}$, et al. Motor learning with augmented feedback: modality-dependent behavioral and neural consequences. Cereb Cortex. (2011) 21:128394. doi: 10.1093/cercor/bhq209

49. Afzal MR, Lee $\mathrm{H}$, Eizad A, Lee $\mathrm{CH}$, Oh $\mathrm{MK}$, Yoon J. Effects of vibrotactile biofeedback coding schemes on gait symmetry training of individuals with stroke. IEEE Trans Neural Syst Rehabil Eng. (2019) 27:161725. doi: 10.1109/TNSRE.2019.2924682

50. Shin J, Chung Y. Influence of visual feedback and rhythmic auditory cue on walking of chronic stroke patient induced by treadmill walking in real-time basis. NeuroRehabilitation. (2017) 41:445-52. doi: 10.3233/NRE-162139

51. Cherry-Allen KM, Statton MA, Celnik PA, Bastian AJ. A duallearning paradigm simultaneously improves multiple features of gait post-stroke. Neurorehabilitation Neural Repair. (2018) 32:810-20. doi: 10.1177/1545968318792623

52. Stoykov ME, Madhavan S. Motor priming in neurorehabilitation. J Neurol Phys Ther. (2015) 39:33-42. doi: 10.1097/NPT.0000000000000065

53. Sivaramakrishnan A, Madhavan S. Combining transcranial direct current stimulation with aerobic exercise to optimize cortical priming in stroke. Appl Physiol Nutr Metabol. (2020). doi: 10.1139/apnm-2020-0677. [Epub ahead of print].

54. Cleland BT, Galick M, Huckstep A, Lenhart L, Madhavan S. Feasibility and safety of transcranial direct current stimulation in an outpatient rehabilitation setting after stroke. Brain Sci. (2020) 10:719. doi: 10.3390/brainsci10100719

55. Kindred JH, Wonsetler EC, Charalambous CC, Srivastava S, Marebwa BK, Bonilha L, et al. Individualized responses to Ipsilesional high-frequency and contralesional low-frequency rTMS in chronic stroke: a pilot study to support the individualization of neuromodulation for rehabilitation. Front Human Neurosci. (2020) 14:578127. doi: 10.3389/fnhum.2020.578127

56. Tsaih PL, Chiu MJ, Luh JJ, Yang YR, Lin JJ, Hu MH. Practice variability combined with task-oriented electromyographic biofeedback enhances strength and balance in people with chronic stroke. Behav Neurol. (2018) 2018:7080218. doi: 10.1155/2018/7080218

57. Bernhardt J, Hayward KS, Kwakkel G, Ward NS, Wolf SL, Borschmann K, et al. Agreed definitions and a shared vision for new standards in stroke recovery research: the stroke recovery and rehabilitation roundtable taskforce. Int J Stroke. (2017) 12:444-50. doi: 10.1177/1747493017711816

58. Stinear C, Ackerley S, Byblow W. Rehabilitation is initiated early after stroke, but most motor rehabilitation trials are not: a systematic review. Stroke. (2013) 44:2039-45. doi: 10.1161/STROKEAHA.113.000968

59. Sun JH, Tan L, Yu JT. Post-stroke cognitive impairment: epidemiology, mechanisms and management. Ann Transl Med. (2014) 2:80. doi: 10.3978/j.issn.2305-5839.2014.08.05

60. Wutzke CJ, Faldowski RA, Lewek MD. Individuals poststroke do not perceive their spatiotemporal gait asymmetries as abnormal. Phys Ther. (2015) 95:1244-53. doi: 10.2522/ptj.20140482

61. Roden-Reynolds DC, Walker MH, Wasserman CR, Dean JC. Hip proprioceptive feedback influences the control of mediolateral stability during human walking. J Neurophysiol. (2015) 114:22209. doi: 10.1152/jn.00551.2015
62. Pietrosimone B, McLeod MM, Florea D, Gribble PA, Tevald MA Immediate increases in quadriceps corticomotor excitability during an electromyography biofeedback intervention. J Electromyogr Kinesiol. (2015) 25:316-22. doi: 10.1016/j.jelekin.2014.11.007

63. Kesar TM, Stinear JW, Wolf SL. The use of transcranial magnetic stimulation to evaluate cortical excitability of lower limb musculature: challenges and opportunities. Restorative Neurol Neurosci. (2018) 36:33348. doi: 10.3233/RNN-170801

64. Porciuncula F, Roto AV, Kumar D, Davis I, Roy S, Walsh CJ, et al. Wearable movement sensors for rehabilitation: a focused review of technological and clinical advances. PMR. (2018) 10(9Suppl.2):S22032. doi: 10.1016/j.pmrj.2018.06.013

65. Poitras I, Dupuis F, Bielmann M, Campeau-Lecours A, Mercier C, Bouyer LJ, et al. Validity and reliability of wearable sensors for joint angle estimation: a systematic review. Sensors. (2019) 19:71555. doi: 10.3390/s19071555

66. Renner KE, Williams DSB, Queen RM. The reliability and validity of the loadsol((R)) under various walking and running conditions. Sensors. (2019) 19:20265. doi: 10.3390/s19020265

67. Schlachetzki JCM, Barth J, Marxreiter F, Gossler J, Kohl Z, Reinfelder S, et al. Wearable sensors objectively measure gait parameters in Parkinson's disease. PLoS ONE. (2017) 12:e0183989. doi: 10.1371/journal.pone.0 183989

68. Balouchestani M, Krishnan S. Effective low-power wearable wireless surface EMG sensor design based on analog-compressed sensing. Sensors. (2014) 14:24305-28. doi: 10.3390/s141224305

69. Hughes J, Iida F. Multi-functional soft strain sensors for wearable physiological monitoring. Sensors. (2018) 18:113822. doi: 10.3390/s181 13822

70. Schliessmann D, Nisser M, Schuld C, Gladow T, Derlien S, Heutehaus $\mathrm{L}$, et al. Trainer in a pocket - proof-of-concept of mobile, realtime, foot kinematics feedback for gait pattern normalization in individuals after stroke, incomplete spinal cord injury and elderly patients. J Neuroeng Rehabil. (2018) 15:44. doi: 10.1186/s12984-0180389-4

71. Lohse KR, Lang CE, Boyd LA. Is more better? Using metadata to explore dose-response relationships in stroke rehabilitation. Stroke. (2014) 45:20538. doi: 10.1161/STROKEAHA.114.004695

72. Cramer SC, Dodakian L, Le V, See J, Augsburger R, McKenzie A, et al. Efficacy of home-based telerehabilitation vs. in-clinic therapy for adults after stroke: a randomized clinical trial. JAMA Neurol. (2019) 76:107987. doi: 10.1001/jamaneurol.2019.1604

73. Dorsch AK, Thomas S, Xu X, Kaiser W, Dobkin BH, investigators S. SIRRACT: an international randomized clinical trial of activity feedback during inpatient stroke rehabilitation enabled by wireless sensing. Neurorehabilitation Neural Repair. (2015) 29:407-15. doi: 10.1177/1545968314550369

74. Gordt K, Gerhardy T, Najafi B, Schwenk M. Effects of wearable sensorbased balance and gait training on balance, gait, and functional performance in healthy and patient populations: a systematic review and metaanalysis of randomized controlled trials. Gerontology. (2018) 64:7489. doi: $10.1159 / 000481454$

Conflict of Interest: The authors declare that the research was conducted in the absence of any commercial or financial relationships that could be construed as a potential conflict of interest.

Copyright (C) 2021 Spencer, Wolf and Kesar. This is an open-access article distributed under the terms of the Creative Commons Attribution License (CC BY). The use, distribution or reproduction in other forums is permitted, provided the original author(s) and the copyright owner(s) are credited and that the original publication in this journal is cited, in accordance with accepted academic practice. No use, distribution or reproduction is permitted which does not comply with these terms. 